\title{
Eosinophilic Gastroenteritis with Involvement of Duodenum and Colon: A Rare Case with Review of Literature
}

\author{
Deepankar Kumar Basak ${ }^{1 *}$, Samsul Arfin², Richmond Ronald Gomes ${ }^{3}$ and Fahim Faruque ${ }^{1}$ \\ ${ }^{1}$ Associate consultant-Gastroenterology, Bangladesh \\ ${ }^{2}$ Gasroenterology Square Hospitals Limited, Bangladesh \\ ${ }^{3}$ Internal Medicine Ad-din Women's Medical College \& Hospital, Bangladesh
}

Submission: March 01, 2017; Published: March 15, 2017

"Corresponding author: Deepankar Kumar Basak, Associate consultant-Gastroenterology Square Hospital Ltd, Dhaka, Bangladesh, Tel: 01760499475; Email: deepankarbasak@gmail.com

\begin{abstract}
Eosinophilic gastroenteritis (EG) is a rare inflammatory disorder of the gastrointestinal tract of unknown aetiology. It is characterized by eosinophilic infiltration of the bowel wall starting from esophagus to rectum most commonly stomach and duodenum, peripheral eosinophilia and various gastrointestinal manifestations. Symptoms mainly depend on the affected digestive segments and the involvement of the different layers of the digestive wall. Diagnosis requires a high index of suspicion and exclusion of various disorders that are associated with peripheral eosinophilia. We report a case of 32 years young man with abdominal pain, vomiting and loose motion, ultimately diagnose as a case of eosinophilic gastroenteritis with involvement of duodenum, proximal jejunum and colon who responded well to steroid.
\end{abstract}

Keywords: Eosinophilic colitis; Pain in abdomen; Colitis; Eosinophilia; Gastrointestinal disease

\section{Introduction}

Primary eosinophilic gastrointestinal disease (EGID), originally described by Kaijser [1] is a rare spectrum of gastrointestinal disorders characterized by inflammation rich in eosinophils, without evidence of known causes for eosinophilia, such as parasitic infection, drug reaction, or malignancy [2]. The disease can affect any segments of the gastrointestinal tract from the esophagus to the rectum, giving rise to various clinical presentations including Eosinophilic Esophagitis (EE), eosinophilic gastritis, eosinophilic gastroenteritis(EG) and Eosinophilic Colitis (EC).

Eosinophilic esophagitis and gastroenteritis is more common but EC is exceptionally rare with only a few cases being reported since 1979 . The absence of defined histological criteria for a specific eosinophils count in the colonic mucosa makes the diagnosis of this entity challenging. Hence, its true frequency is not clear. The clinical presentation includes abdominal pain diarrhea (bloody or non-bloody), and/or weight loss. EC in its primary form can be associated with other atopic conditions. Colonic eosinophilia cans also occured secondary to helminthic infections (e.g. pinworms, hookworms), inflammatory bowel disease, autoimmune disease (e.g. scleroderma, Churg Strauss syndrome), celiac disease, drug reactions and in association with the HES.

Since secondary eosinophilic inflammation may occur in numerous gastrointestinal disorders such as IgE-mediated food allergy, gastro esophageal reflux disease and inflammatory bowel disease, the true incidence and prevalence of primary EGID remains largely unknown. A recently established worldwide-web registry found that EGID mainly affects the pediatric population, although it has been reported in patients up to 68 years of age [3]. In the past few years, EE has been increasingly recognized as a distinct condition that affects about $1 \%$ of the population, and accounts for dysphagia and food impaction that remain nonresponsive to traditional anti-reflux management, both in pediatric and adult gastroenterology [4]. Accordingly several excellent reviews on EE have recently been published [4-6]. In contrast, EC represents the least frequent manifestation 
of EGID whether or not it presents with disease in other segments of the gastrointestinal tract. $3 \mathrm{EC}$ appears to have a bimodal distribution that affects neonates with a relatively high prevalence and a separate group of young adults with no gender preference.

\section{Case Report}

A 32-years-old young man was admitted with 1 week history of progressive abdominal discomfort, vomiting and diarrhea which was aggravated by taking meals. Stool was watery in nature, 10-12times/day but not mixed with blood. He mentioned similar type symptoms many times but last one was few months back, since then he lost $4 \mathrm{~kg}$ wt. He had no history of abdominal surgery or any known food allergy. He had a history of skin disease from childhood, most probably ichthyosis vulgaris, for this reason he currently not taking any treatment. He denied taking any drugs or herbal medicines. On clinical examination, he
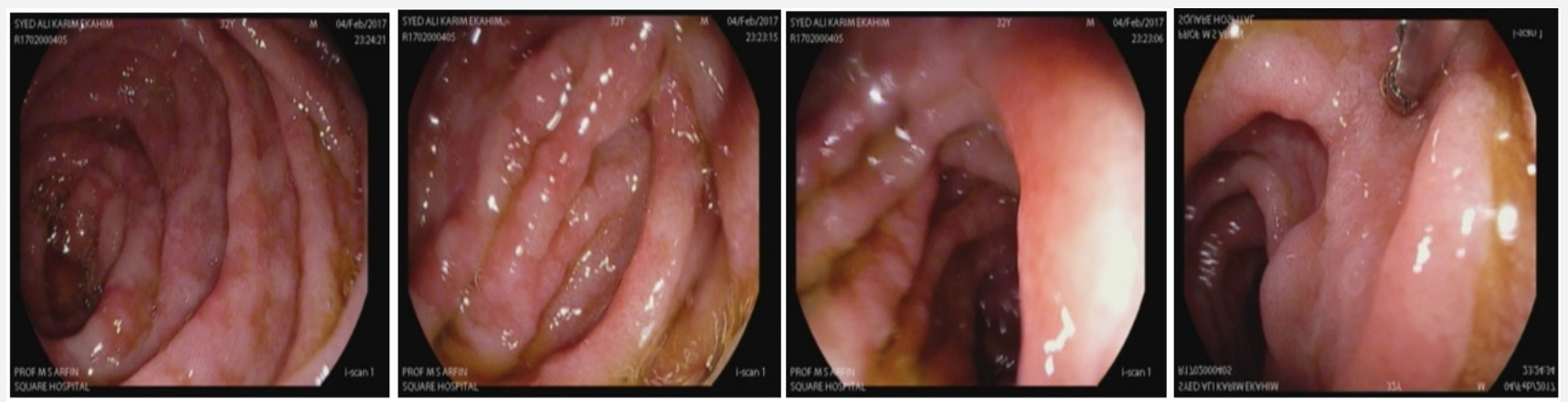

Figure 1: Inflamed and ulcerated at duodenum and proximal jejunum.

On colonoscopy showed multiple ulcers and inflamed patches at the rectum and sigmoid colon. Multiple ulcers and heaped up appeared dehydrated and vitals were normal. His abdomen was soft and slightly distended. Laboratory investigations showed a high white cell count of $16.3 \times 109 / \mathrm{L}$, with raised eosinophils count of $40.1 \times 109 / \mathrm{L}$. The hemoglobin level and platelet counts were normal. The liver function tests, erythrocyte sedimentation rate, C-reactive protein and autoimmune antibody screen were normal. The serum immunoglobulin-E (IgE) was highly raised at $1044 \mathrm{IU} / \mathrm{ml}$ (normal reference range, less than $128 \mathrm{IU} / \mathrm{ml}$ ). Stool culture for pathogens and analyses for ova, cysts and parasites were negative. USG of abdomen and x-ray abdomen was unremarkable. Skin consultation was taken and diagnosed as ichthyosis vulgaris for this reason treatment is started.

Endoscopy revealed mild form of monilial esophagitis at lower end of esophagus but mucosa of at the bulb and post bulbular area, second part of duodenum and proximal jejunum is severely inflamed and ulcerated at places (Figure 1). Multiple Biopsies was taken from duodenum and proximal jejunum.
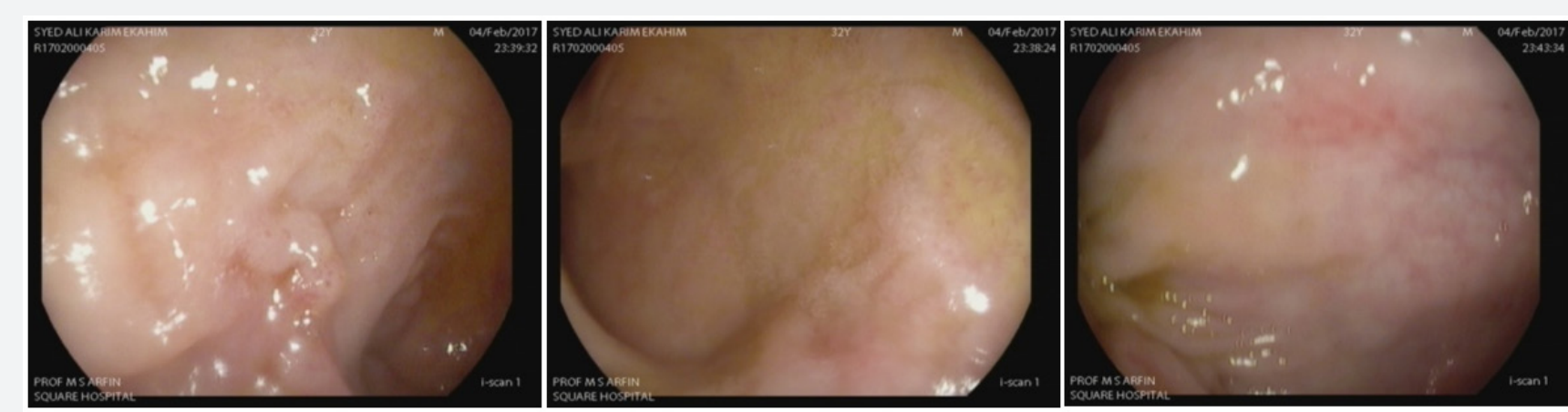

Figure 2: Multiple ulcer and inflamed patches at rectum sigmoid colon and terminal ileum.

Biopsy report of duodenum and proximal jejunum revealed diffuse infiltration of inflammatory cells including a fair number of eosinophils (>40/hpf). Small number of plasma cells, lymphocytes \& polymorphs are also present. The surface is focally eroded. No evidence of malignancy is seen.

Biopsy report of rectum and sigmoid colon showed focal erosion. Lamina propia shows mild congestion and diffuse lesions is seen at the terminal ileum (Figure 2). Biopsy was taken from terminal ileum and rectum. infiltration of a fair number of eosinophils and plasma cells. Eosinophilic cystitis is noted lymphoid follicle is formed.

Mucosa of terminal ileum showed some of villi are shortened and broad. The lamina propia shows dense infiltration of chronic inflammatory cells including fair number of eosinophilic and plasma cells. Lymphoid follicles wit prominent germinal centre are present. Surface is focally eroded. 
He was treated with oral prednisolone ( $30 \mathrm{mg}$ daily). His symptoms improved and the serum white cell and eosinophils counts returned to normal levels after 5 days. The steroid dose was gradually tapered at follow-up as outpatient and successfully stopped a year later. He has remained symptom-free for more than 3 years post-treatment.

\section{Discussion}

Eosinophilic gastroenteritis is a rare, benign inflammatory disorder of the gastrointestinal tract, characterized by Eosinophilic infiltration of the bowel wall, in the absence of known causes of Eosinophilic, including drug reaction, parasitic infections and malignancy [1,3]. Eosinophils in the gastrointestinal tract are responsible for innate immunity to parasites, regulation of lymphocytes, antigen presentation and protection against tumors. Nevertheless, over-stimulation of eosinophils generates excessive degranulation which can lead to severe inflammation, production of neurotoxins and reactive oxygen species which are responsible for the typical symptoms of eosinophilic gastroenteropathy $[6,7]$.

EGID in general has three hallmarks including peripheral eosinophilia (typically in the range of $5 \%$ to $35 \%$ ), segmental eosinophilic infiltration of the gastrointestinal tract and functional abnormalities [7,8]. Importantly, up to $23 \%$ of patients with primary EGID have no peripheral eosinophilia. EG affects all ages of both genders and diagnosed most frequently in the third decade of life [2,3]. EG mainly involves the stomach and duodenum $[1,2]$. The pathogenesis and aetiology remain unclear. A personal or family history of allergic disorder is reported in $70 \%$ of patients with this disorder.

EG should be considered in the differential diagnosis of unexplained gastrointestinal symptoms, especially in the presence of peripheral eosinophilia. The 3 main diagnostic criteria are:

(i) The presence of gastrointestinal symptoms.

(ii) Biopsies showing eosinophilic infiltration of one or more areas of the gastrointestinal tract $(>20$ eosinophils per high power field) or typical radiological findings with peripheral eosinophilia.

(iii) No evidence of parasitic or extra-intestinal disease. Histopathology is the gold standard for diagnosis [1,3]. Depending on the location of the compromised tissue, eosinophilic gastroenteropathy may be identified as esophagitis, gastritis, duodenitis or colitis. The last is exceptionally rare and only a few cases have been reported since 1979. It has very non-specific symptoms of fever, diarrhea, abdominal pain and weight loss.

In 1970, Klein classified this disease according to the depth of involvement:

a) The Mucosal Form (25\% to $100 \%)$ most often affects the stomach and is manifested by anemia, fecal blood loss and weight loss. b) The Muscular Form (13\% to $70 \%$ ) manifests through nausea, vomiting, diarrhea, abdominal cramps, and intestinal obstruction.

c) The Serosal Form (12\% to $40 \%$ ) manifests through eosinophilic ascites, high levels of peripheral eosino $\neg$ philia and severe inflammation $[8,9]$.

EG is usually patchy in distribution. Invasive laparotomy or laparoscopic full thickness biopsy may need to be performed to diagnose subserosal disease. Peripheral eosinophilia is seen in up to $80 \%$ of cases of EG [2,3]. Raised serum IgE, as seen in our patient, was reported to be more prevalent in children with EG. A multidisciplinary task force has recently reached consensus on the diagnostic criteria of EE, including the presence of more than 15 eosinophils per high-power field in the esophageal squamous mucosa. No such consensus exists for EG \& EC, although most authors have used a diagnostic threshold of 20 eosinophils per high-power field. Of note, normal values for tissue eosinophils vary widely between different segments of the colon, ranging from 30 in the caecum, thus location of the biopsy is critically important for interpretation of findings.

More or less prominent tissue eosinophilia in the colon may result from a number of conditions and EC remains therefore a diagnosis of exclusion. Colonoscopic biopsies obtained from patients with inflammatory bowel disease, in particular with Crohn's colitis, often show severe tissue eosinophilia. Parasitic infection of the colon with pinworms, roundworms, or whipworms may lead to marked eosinophilic infiltration, and repeated stool or serological testing may be needed to reveal this specific etiology. Drug-induced EC has been described in response to clozapine, carbamazepine, rifampicin, non-steroidal anti-inflammatory agents, tacrolimus and gold. EC has also been associated with autoimmune connective tissue disease including scleroderma, dermatomyositis and polymyositis as well as with allogeneic bone marrow transplantation and the rare TolosaHunt syndrome that features inflammatory ophthalmoparesis. The idiopathic hypereosinophilic syndrome (HES) may also affect the colon, but this rare condition presents with sustained and marked peripheral eosinophilia with end-organ damage that extends beyond the gastrointestinal tract (e.g. heart and skin).

Diagnosis of $80 \%$ of these patients is done through upper digestive tract endoscopy of the stomach and small intestine and colonoscopy with tissue biopsy. In most cases, macroscopic study of the gastrointestinal mucosa shows normal mucosa, slight edema and congestion, and even ulcers or lesions with nodular configurations. Ninety percent of patients with EG respond to steroid therapy, and more dramatic response is usually seen in the serosal subtype $[2,3]$. The duration of steroid therapy reported in the literature is variable. Other treatment options include dietary modification, leukotriene receptor antagonists, mast cell stabilizers, and antibodies against interleukin-5 and IgE $[1,3,5]$. Surgical intervention may be required for cases where a definitive diagnosis cannot be made or when perforation or significant obstruction occurs [1,3]. The natural history of EG is 
unclear, emphasizing the need for long-term follow-up studies for patients with EG. Our patient needs to follow-up [10,11].

\section{Conclusion}

In summary, we present a rare case report of Eosinophilic gastroenteritis and colitis diagnosed on histopathology and respond to steroid therapy. Clinician should be aware of this rare entity as it can mimic several other gastrointestinal disorders.

\section{References}

1. Khan S, Orenstein SR (2008) Eosinophilic gastroenteritis. Gastroenterol Clin North Am 37: 333-348.

2. Talley NJ, Shorter RG, Phillips SF, Zinsmeister AR (1990) Eosinophilic gastroenteritis: A clinicopathological study of patients with disease of the mucosa, muscle layer and subserosal tissues. Gut 31(1): 54-58.

3. Chen MJ, Chu CH, Lin SC, Shih SC, Wang TE (2003) Eosinophilic gastroenteritis: clinical experience with 15 patients. World J Gastroenterol 9(12): 2813-2816.

4. Rothenberg ME (2004) Eosinophilic gastrointestinal disorders (EGID). J Allergy Clin Immunol 113(1): 11-28.
5. Sheikh RA, Prindiville TP, Pecha RE, Ruebner BH (2009) Unusual presentation of eosinophilic gastroenteritis: Case series and review of literature. World J Gastroenterol 15(17): 2156-2161.

6. Hepburn IS, Sridhar S, Schade RR (2010) Eosinophilic ascites, an unusual presentation of eosinophilic gastroenteritis: A case report and review. World J Gastrointest Pathophysiol 1(5): 166-170.

7. Alfadda AA, Storr MA, Shaffer EA (2010) Eosinophilic colitis: epidemiology, clinical features, and current management. Ther Adv Gastroenterol 4(5): 301-309.

8. Alnaser S, Aljebreen AM (2007) Endoscopic ultrasound and histopathologic correlates in eosinophilic gastrienteritis. Saudi J Gastroenterol 13(2): 91-94.

9. Roufosse FE, Goldman M, Cogan E (2007) Hypereosinophilic syndromes. Orphanet J Rare Dis 2: 37.

10. Kaijser R (1937) Zur Kenntnis der allergischen affektionen des verdauungskanals vom standput des chirurgen aus. Arch Klin Chir 188: 36-64.

11. Rothenberg ME (2004) Eosinophilic gastrointestinal disorders (EGID). J Allergy Clin Immunol 113(1): 11-29.

\section{Your next submission with Juniper Publishers} will reach you the below assets

- Quality Editorial service

- Swift Peer Review

- Reprints availability

- E-prints Service

- Manuscript Podcast for convenient understanding

- Global attainment for your research

- Manuscript accessibility in different formats

( Pdf, E-pub, Full Text, Audio)

- Unceasing customer service

Track the below URL for one-step submission https://juniperpublishers.com/online-submission.php 